\title{
The Legal Risk of Human Enhancement Technology and Its Regulation in China
}

\author{
Qiran Sun \\ University of Science and Technology of China, Hefei, China \\ Email: sqr1216@163.com
}

How to cite this paper: Sun, Q. R. (2021). The Legal Risk of Human Enhancement Technology and Its Regulation in China. Open Journal of Social Sciences, 9, 39-53. https://doi.org/10.4236/jss.2021.95004

Received: April 18, 2021

Accepted: May 8, 2021

Published: May 11, 2021

Copyright $\odot 2021$ by author(s) and Scientific Research Publishing Inc. This work is licensed under the Creative Commons Attribution International License (CC BY 4.0).

http://creativecommons.org/licenses/by/4.0/

\section{(c) (i) Open Access}

\begin{abstract}
As technology advances, our ability to intervene with ourselves has reached an unprecedented height, and "human enhancement" has come into being and discussed by the public. This paper holds that human enhancement behavior is based on mutual voluntary medical service behavior, which is essentially a civil legal act. In reality, human enhancement may be abused under the dual inducement of commercial interests and social needs as the technology develops. The Chinese government has the responsibility to be a major part in the process of regulating the technology by law in order to minimize its harmful impact on public stability. But some problems still exist, such as vague regulatory standards, unclear regulatory authorities, insufficient legal responsibility response and imperfect relief procedures. This paper focuses on the legal issues brought about by human enhancement and discusses it in a systematic way, and tries to put forward suggestions that could function with China's national conditions. As for the bottom line of human enhancement, reproduction gene enhancement should be absolutely prohibited, and other enhancement methods should be conditionally restricted. In terms of the overall regulation path, it should focus on legal provisions, and implement the regulation mode by both mild and strict laws. China should also set up special agencies and implement strict access mechanism. At the same time, the industry association should formulate the corresponding technical norms and cultivate the scientific concept of the public, in order to improve the effect of legal regulation.
\end{abstract}

\section{Keywords}

Human Enhancement Technology, The Legal Risks, Legal Regulation

\section{Introduction}

With the rapid development of science and technology, a series of human en- 
hancement technologies have emerged that can directly interfere with the human body. Human can use these technologies to cure diseases or to strengthen their physical strength. Human enhancement technologies have huge significance for human development, with those technologies, human beings are able to gain unprecedented power, and become stronger than ever before. But human enhancement technology can also bring us legal, ethical and social problems that should not be ignored.

Human enhancement technology can be dangerous, and we should not ignore its potential risk and make it develop in an uncontrolled way. We must discover its ethical and legal risk through in-depth reflection and research, fully consider its connection with social values and ethical standards, and therefore build up the appropriate legal regulation system and find a balance between humanity and technology.

The study on the legal issues of human enhancement technology needs to start with discussing the legal risks that may be brought by human enhancement technology, and formulate a reasonable legal regulation system in order to make the development of human enhancement technology have a positive impact on the society.

\section{An Overview of Human Enhancement Technology}

What human enhancement technology is, what types human enhancement technology is divided into, and what its legal nature is, are directly related to our understandings of the legal risks of human enhancement technology, and the discussion of these problems is the basis of solving the legal risks of human enhancement technology.

\subsection{Definition of Human Enhancement Technology}

In the long history of human development, we have never abandoned the desire to improve ourselves. With the rapid development of science and technology today, the mysteries of human body and mind are constantly being solved. Human beings today improve their minds through education, strengthen their bodies through physical exercise, and protect themselves from being hurt with weapons and shields. The idea of human empowerment is undergoing a revolutionary change as the human race begins to enhance itself through emerging science and technology.

Human enhancement has been given a new meaning in the modern context, referring to "the application of gene technology or biotechnology for the purpose of improving human ability or happiness" (Giubilini and Sanyal, 2015). There are two aspects of human enhancement right here, first, human beings are already able to apply scientific means directly to the human body, and even put technological products directly inside the human body and make them function inside. Second, this enhancement has moved beyond the therapeutic realm and into the broader realm of human enhancement (Earp et al., 2014). 


\subsection{Types of Human Enhancement}

Human enhancement can be divided into four specific types: physical enhancement, mental enhancement, moral enhancement and compounded enhancement.

Physical enhancement refers primarily to beneficial changes in bodily functions through technology. These changes fall into two categories: the first is to enhance the body's existing functions, the second is to add new functions that never exist in the human body. The difference between human enhancement technology and traditional medical treatment is that traditional medical treatment can only restore the human body's ability to the maximum, while human enhancement technology can fundamentally change the human's physical function.

Mental enhancement includes cognitive enhancement and emotional enhancement. Cognitive enhancement refers to strengthening the human mind by improving and expanding the human body's ability to process information (Bostrom and Sandberg, 2009). Relevant research mainly uses drugs, surgery and other means to improve people's memory, attention, or logic. Emotion enhancement is more complicated, since the essence of "emotion" is a variety of coping modes of the body to environmental changes, and it is a complex mechanism unique to human beings (Levenson, 1994). Emotion enhancement refers to the use of scientific and technological means to enhance or suppress human emotions, achieve emotional control, and maximize the benefits of positive emotions.

Moral enhancement refers to the enhancement of human's existing moral cognition and understanding through various technical means. In fact, moral enhancement and cognitive enhancement have a lot in common with each other, because many moral judgments are based on cognitive abilities, such as self-reflection, cost estimation, and so on (Douglas, 2014). Therefore, it can be seen that ability plays a very important role in moral judgment, and better cognitive ability is likely to lead to the improvement of moral level (Persson and Savulescu, 2012).

Compounded enhancement takes convergent technology as the core to realize the integration of human and machine. Convergence technology integrates nanotechnology, biotechnology, information technology and cognitive science. There are complementary and close relationships among these four technologies. Using convergence technology, information can be transmitted between the brain and the device, making human-device communication possible.

\subsection{The Legal Nature of Human Enhancement Technology}

In order to study how to regulate human enhancement technology by law, the legal nature of human enhancement technology is analyzed. The identification of the legal nature of human enhancement technology plays a fundamental role in the discussion of its legal risks and regulations, so it is necessary to analyze and summarize the legal nature of human enhancement technology. 
First of all, human enhancement is a kind of legal action. The acceptor of human enhancement has his/her purpose in the legal relationship, so human enhancement is not a factual act. In addition, human enhancement must be carried out with the express consent of both the enhancement provider and the enhancement recipient, as evidenced by written agreement, so it is not a quasi-legal act.

Second, human enhancement is a civil legal act. Firstly, both the provider of enhancement technology and the receiver of enhancement technology are equal civil subjects. Secondly, both the enhancer and the enhancer are willing to implement human enhancers. Finally, the technology provider is responsible for making human enhancements, and the recipient pays for them, in accordance with the principle of paid parity. However, this paper is against treating human enhancement as a purely civil legal act, because human enhancement technology will affect the natural development process of human beings to a great extent (Hong, 2011).

Third, human enhancement is a medical service behavior. Although most of the people served by human enhancement are those who are pathologically healthy, they receive human enhancement not for the purpose of curing disease, but for the purpose of fulfilling their desire to enhance themselves. However, although accepting human enhancement or not have nothing to do with health, human enhancement also need highly professional physicians to complete. From this perspective, human enhancement is not different from the traditional medical behavior.

\subsection{Existing Research on the Legal Aspect of Human Enhancement Technology}

Ruth Chadwick subdivides the types of human enhancement (Chadwick and Felicity, 2008). He argues that, unlike therapy, human enhancement intervenes artificially to improve the basic functions of the body. George Khushf proposed that the initial stage of human enhancement is to improve human functions one by one through medical means, and then increase functions quantitatively on the basis of enhanced functions (Khushf, 2008). Julian Savulescu, through the analysis of definitions of various reinforcement concepts, believes that any change in human biology or psychology can be regarded as human enhancement as long as it can make people have a greater possibility to live a happier life (Savulescu, 2010). Mehlman believed that if human enhancement technology was put into the market and allowed to be affected by market rules, the price of enhancement technology would be very expensive and become an exclusive luxury for the rich, which would inevitably enlarge the existing gap between social classes (Mehlman and Botkin, 1998). Adams proposed that in the process of applying human enhancement techniques, different enhancement techniques could be treated differently through a grading system (Adams, 2010). Renzong Qiu believes that human enhancement means to enhance people's ability to understand the world, improve people's mood and physical strength through artificial means rather 
than natural means, in order to achieve the purpose of prolonging human life and make people healthier and happier (Qiu, 2008). Ye Feng discusses the possible ways and potential consequences of using nanotechnology to enhance human beings, pointing out that using nanotechnology to edit human genes will affect the natural process of human development. The bottom-line principle of enhancing human beings through nanotechnology must be formulated, that is, the first is to follow the principle of harmless and beneficial, and the second is that the application of nanotechnology should not break the boundary of "human" (Feng, 2012). Javor et al. point out that neuro-enhancement technology can be used by advertisers to analyze the characteristics of the human brain to tailor ads that are more appealing to specific groups, improve the effectiveness of advertising, and so on (Javor et al., 2013). Xuan Jiang believes that there are many problems with non-therapeutic gene sequence modification, and we should not avoid the challenges brought by technology. Instead, we should actively face the gene enhancement technology and appropriately limit the application of technology (Jiang, 2015).

\section{The Legal Risks of Human Enhancement Technology}

No technology can be completely safe. As one of the emerging technologies, human enhancement technology inevitably has many risks and hidden dangers. Although human enhancement technology has been making breakthroughs, its potential risks are still huge. The risk of technology itself refers to the risk caused by the immaturity of technology and the risk caused by operation error during the implementation of enhancement technology. It is the existence of technical risk that determines the application of human enhancement technology will inevitably bring various legal risks.

\subsection{Against Justice and Human Dignity}

Fairness and justice are the lofty value of law, and it is the priority for a country. Justice is not only limited to the agreement between individuals, but also has far-reaching significance for the survival of groups. Human enhancement technology is not only related to the overall interests of human beings, but also related to the long-term development of human beings. Once the human enhancement technology is abused, it is easy to exacerbate the gap between the rich and the poor, and even cause devastating disasters.

It is feared that the development and application of human enhancement technologies will further exacerbate the already prominent gap between the rich and the poor and cause even more serious social problems. Only the rich and privileged few can afford human enhancement technology, and after they use it to significantly improve their physical function and cognitive ability, these privileged classes can access more social resources and opportunities. Once human enhancement technology is widely used, the current inequality may enlarge in an unexpected way, further exacerbating social contradictions and threatening social stability. In fact, there is some dissent to this view, as some scholars argue 
that genetic differences bring huge inequality, and we need human enhancement technology to minimize those differences.

Equality is the basic attribute of law. In real life, there are huge gaps in the availability of medical services and the level of medical care between different social classes. However, after the application of human enhancement technology, such gap will inevitably evolve into an insurmountable gap. If the market is allowed to evolve and the scope of enhancement continues to expand, human enhancement technology will be completely become the "privilege" of the rich.

It can be seen that unrestricted use of human enhancement could turn a technology that is supposed to be dedicated to human into a genetic weapon. In the long run, social equality will face great challenges and social order will be greatly threatened.

\subsection{Infringe the Patient's Legal Rights}

Due to the particularity of human enhancement technology, the use of human enhancement technology may infringe patients' informed consent rights and genetic privacy rights.

From the perspective of informed consent, the communication gap between doctors and patients has widened further due to the greater complexity and risks of emerging technologies. In the new era of rapid development of technology, genes that humans once thought could not be interfered with have become objects that can be modified. Therefore, the "theory of the omnipotence of science and technology" is rampant. Human rationality and the limitation of scientific and technological development have been left behind, and many people have ignored the potential defects and harm of human enhancement technology. Human enhancement technology has its own limitations, and it contains various risks. For example, the enhancement procedure may lead to several diseases if it is not done correctly. Those risks may be difficult for the recipient of enhancements to understand.

From the perspective of genetic privacy rights, genes are unique to each individual and contain all the secrets of the genetic information of all individuals, even the secrets of the genetic characteristics of an entire country or race. If a person's genetic information is leaked, his personal information and family information will be exposed and cause a series of social ethical problems and public security problems. Protecting everyone's genetic privacy is not only a respect for individual personality in society, but also a necessity to ensure social stability. If the patient's genetic privacy rights aren't properly protected, his/her dignity cannot be ensured as well.

China started late in the field of gene technology, and the research on gene privacy also started late. At present, there is little research on related aspects, and there is almost no research on gene legislation in other countries. At present, there is no relevant gene privacy protection law in China's legislation, and the protection of gene privacy is only scattered in a series of legal provisions, which has not really become a complete system. Obviously, at the present stage, Chi- 
na's legislative protection of gene privacy is still insufficient and urgently needs to be strengthened.

\subsection{Increase the Difficulty of Determining the Liability of Medical Damage}

With the application of human enhancement technology, the identification of medical damage liability has become more and more complicated, and the following two problems may occur:

First, in the current judicial practice of medical injury disputes, forensic expertise plays a vital role in proving the causal relationship between illegal facts and damage results. However, we should note that the causality stated in relevant civil law theories refers to legal causality, and the causality judgment conclusion made by medical appraisal is only factual causality, while the legal causality should be comprehensively judged by the judge on the basis of the factual causality conclusion made by medical appraisal. But in judicial practice, judges often take the conclusions of judicial expertise directly as the basis for judgment. Therefore, the judgment result will inevitably violate the legal provisions of the situation.

Second, there are some problems in forensic expertise itself. The essence of appraisal is the scientific analysis and judgment made by experts with their professional scientific knowledge and experience. Therefore, "being professional" should be the first requirement to the appraiser. According to the provisions of China's Civil Procedure Law, if the people's court deems it necessary to conduct appraisals, it shall entrust qualified appraisers to conduct appraisals. The appraiser needs plenty medical knowledge and clinical experience. With the application of human enhancement technology, the medical disputes caused by it will certainly put forward higher professional level requirements for appraisers.

If the liability of medical damage cannot be correctly determined, it will create an obstacle when protecting the victim's legal rights.

\section{The Deficiency of the Existing Legal Regulation System in China}

\subsection{Vague Regulation Standard}

At present, the Biosafety Law of the People's Republic of China has been implemented since April 15, 2021. The main legislative purpose of the Biosafety Law is to safeguard national security, and prevent biosafety risks, but since the scope of regulation is relatively broad, the details are somehow ambiguous.

This paper argues that we can use more flexible social norms for regulation and control. For example, an industry association composed of researchers can formulate a professional specification by itself. As a legal person, the implementation of the documents formulated by the industry association does not rely on the coercive power of the state, but is carried out through the mechanism of voluntary identification, peer reputation punishment and responsibility sharing 
generated by internal consensus. In fact, in order to meet the public's expectation of biomedical technology innovation, uphold the attitude of prudent regulation of frontier fields, and cater to the trend of co-governance between the state and society, China should exert its efforts to give play to the substantive role of social groups and experts. This paper believes that social norms can play an indispensable role in the regulation of human enhancement technology.

However, the social norms formed in this way also have certain pitfalls. When researchers create social norms by themselves, there is a danger that experts "make laws by themselves" and may fall into the quagmire of science administration orientation. It is difficult for the public to determine the neutrality and appropriateness of "self-legislation" by experts. It is likely that the huge profits generated by human enhancement industries will bring researchers and capitalists closer together, allowing the experts who set the rules to yield to the temptation of money.

\subsection{Unclear Regulations}

According to the Regulations on the Management of Medical Institutions, medical institutions should be supervised by the health commission. Obviously, the application of human enhancement technology should also be regulated. According to the Biosafety Law, the relevant work of biosafety shall be the responsibility of the relevant departments of the local people's governments at or above the county level. It is not difficult to see that the provisions of the Biosafety Law on the supervision of new biomedical technologies are relatively general, and "the Regulations on the Administration of Clinical Application of New Biomedical Technologies" issued by the National Health Commission in 2019 also specify the competent departments of relevant technologies.

In addition, the regulations also stipulate that clinical research of these technologies should be administered in a hierarchical manner. However, the regulations are vague on the clinical application of new biomedical technologies, and merely stipulate that "the clinical application shall be administered by the competent health department under the State Council". However, the National Health Commission has a large number of institutions, including more than 20 internal institutions such as the Medical Administration and Medical Administration, the Grassroots Health Department, and the General Supervision Bureau. The functions and powers of these internal institutions also overlap and overlap to a certain extent, and the boundaries are very vague. If it is not clear which internal organization is responsible for the supervision, mutual evasion and competition for power may occur, and the supervision of the clinical transformation and application of new technologies will be ineffective.

Moreover, there may be some drawbacks to having the National Health Commission regulate the use of human enhancement technologies. New biomedical technologies such as human enhancement technology are highly advanced, and the National Health Commission has been inclined to regulate "tra- 
ditional medical practices" and lacks experience in the regulation of new technologies. Due to China's huge population and vast territory, the supervision of clinical application by the National Health Commission is likely to be ineffective and lagging behind.

\subsection{Insufficient Legal Response}

At present, China has not formulated a single law on the criminal responsibility of the abuse of cutting-edge biotechnology and the corresponding supporting provisions. For some behaviors that may bring bad influence and great harm to the society, there is still a lack of effective penal punishment measures. Today, with the rapid development of life science and technology, if we continue to turn a blind eye to this kind of behavior and do not regulate it, then the development of technology will inevitably lead to the continuous reduction of the use cost of life science and technology, and similar abuses will inevitably become inevitable. It is because we can see the possibility of life science and technology being abused that we must regulate it through criminal law.

In this paper, the abuse of human enhancement technology and other cutting-edge biotechnology should be considered as crime of the following reasons: First, the social harm is serious. Biotechnology has enormous risks to society that are unpredictable and irreversible. Frontier biotechnology such as human enhancement technology is not only technically risky, but also ethically damaging. Second, the requirement of the precautionary principle of risk society. The development of science and technology has brought various crises and risks to the society. To control these risks, it is not only necessary to fill in the gaps or omissions in relevant systems, but also necessary to foresee the existence of non-compliance with the system and regulate those behaviors with the criminal law. Third, the coexistence of legal norms and technological development. On one hand, we cannot be too conservative to emphasize the stability of criminal law norms, do not pay attention to the risk of life science new technology, otherwise it will only make the criminal law become more and more unsuitable for the needs of The Times; on the other hand, the norms of criminal law should not impede technological progress and affect human well-being. Therefore, the active involvement of criminal law and the delineation of clear boundaries for researchers can guarantee the freedom of scientific research.

\subsection{Imperfect Relief Work}

There are three ways of relief in civil disputes: self-help relief, social relief and public relief. The Tort Liability Law of the People's Republic of China has also set up a relief system, compared with infringement, in China, medical service provider clearly has a dominant position on disputes caused by human enhancement technology, as a medical institution has sufficient funding and professional workers. There exists a wide gap between the two sides, and it is very difficult for patients to rely on their own strength to negotiate with the medical institutions, the possibility of reaching an agreement between the two sides is 
relatively small.

In the current judicial practice, all kinds of medical injury disputes are often settled through litigation and arbitration. Proving the causal relationship between the illegal fact and the relevant damage is often the top priority. At the present stage, China has not clearly stipulated the distribution of causality of medical injury, so the distribution of the burden of proof of causality is also different in judicial practice. In judicial practice, the trial judge will usually base on the two ways of medical damage causation to prove ownership allocation $(\mathrm{Wu}$, 2018): first, using the principle of general rule in the tort liability law distributes all responsibility of proof to patients. The patient must provide full and effective evidence to prove that there is a causal relationship between the behavior of the medical institution and the damage. Second, since the Tort Liability Law does not allocate the burden of proof for causal relationship, according to the provisions of the Civil Procedure Law on evidence, when patients exhaust their ability to prove, the burden of proof can also be transferred to the medical institution (Zheng, 2020). In either case, the burden of proof is at least to some extent on the patient. Require patients vulnerable to damage, however, the fact of the evidence to bear all the burden of proof is very difficult, especially for frontier biotechnology issues such as human enhancement. It is too difficult for a patient to form a complete chain of evidence.

After all, we can see that after the occurrence of medical injury disputes, there are some difficulties for patients in self-help, social relief and public relief. Clearly, in order for human enhancement technologies to have the greatest impact on human well-being, we must open up avenues for relief, both to promote the adoption of emerging technologies and to protect the legitimate rights of patients.

\section{Suggestions on Legal Regulation of Human Enhancement Technology}

Legal regulation is the product of human reason and embodies the modern effect of law. As for human enhancement technology, China should have its own principled stand, which should not only consider people's life and health and social ethics, but also ensure the orderly development of human enhancement technology, and give full play to the great power of scientific and technological innovation for social progress.

\subsection{Clarify the Boundaries of Human Enhancement}

Whether the characteristics of human genes play a decisive role in human development has always been a controversial topic. According to the current level of technological development, gene enhancement can be divided into two methods: somatic cell gene enhancement and germ cell gene enhancement. Germ cell gene enhancement will have a lasting impact on the offspring and has a higher risk and uncertainty. In addition, this enhancement also involves complex ethical issues, and there is also a widespread opposition to the clinical use of 
gene editing by the scientific community. The germ cell gene enhancement technology must be strictly prohibited in order to prevent its hazards.

Somatic genetic enhancements and other enhancement technology, for example, drug enhancement, surgical enhancement and cosmetic enhancement, have fewer potential hazards than germ cell gene enhancement. People have their right to choose their own way of life and happiness, and it is inappropriate to strictly prohibit those kinds of enhancements. The government may carry out an effective and reasonable supervision on these enhancements, and give full play to the technology's positives while avoiding its negative effect. Any kind of high-tech research and application will inevitably bring different degrees of risk, and in order to avoid the risk of human enhancement technology, the regulations should play their part.

\subsection{Improve Relevant Legislation}

There must be targeted laws and regulations to guide and regulate the implementation of human enhancement technology. The bottom line and principle of human enhancement can be determined in the form of legislation. This paper argues that China can adopt the legislation mode of hard law as the main law and soft law as the auxiliary law to effectively regulate the use of human enhancement technology.

In the process of technological development, the technology community tends to exaggerate the benefits of emerging technologies, but often downplays the risks behind the technology. Therefore, in order to balance innovation with the public interest, it is necessary to make the process of regulation in the field of science and technology more transparent. This paper argues that China should adopt legislation to regulate human enhancement technology, and ensure the enforcement of these legal provisions. Moreover, laws concerning human enhancement technologies must also conform to morality, and only laws that conform to moral requirements can be recognized by the broad masses of people. In terms of the specific regulation content, this paper argues that the boundary of human enhancement behavior must be strictly restricted, and the obligations of medical institutions must be clearly defined.

\subsection{Strengthen Supervision}

This paper argues that a special agency should be set up to regulate the use of human enhancement technology. In the practical application of human enhancement, a preliminary review should be conducted by an ethics committee within the medical institution, followed by a final review by a specialized agency. There is a huge connection between human enhancement technology and the life and health of the public, at the current technical level is difficult to estimate the potential risk of human enhancement technology. Therefore, public power should be put into use in order to establish a more perfect regulatory system. Moreover, this paper argues that we should not only rely on post-regulation to regulate human enhancement, but should take pre-regulation as the priority. 
Due to the importance of human enhancement technology, it is difficult to recover the consequences caused by the abuse of technology through post-supervision.

Restrictive licensing of human enhancement technology can not only protect citizens' right of individual claim, guarantee citizens' right to decide their own way of life and pursuit of happiness, but also prevent the danger caused by the abuse of technology, thus protecting social stability and public life and health.

To be specific, this paper holds that the Human Enhancement Technology Administration Bureau can be set up under the National Health Commission to supervise the related business of human enhancement technology, and to examine whether human enhancement technology can be used in a case. Internal also can undertake more precise division of labor, the agency may establish ethics panel, biotechnology expert group, legal experts and so on, from various angles to fully review of each case, the panel should also discuss with each other, exchange of views between, finally reached an agreement, to ensure the fair and reasonable final decision. In addition to reviewing the application of human enhancement technologies, the agency should also exercise a regulatory role and closely monitor the compliance of medical facilities with the application of technologies and ethical reviews.

According to the "Measures for the Ethical Review of Biomedical Research Involving People", all medical institutions involving biomedical research involving people should establish an ethics committee. Human enhancement technology is highly professional and particular, so the medical institution's ethics committee should not only include experts in the field of ethics and law, as biomedical experts should be also introduced as well. Only in such way can the medical institution carry on an effective, scientific and ethical review on human enhancement technology.

Also, the qualification of using human enhancement technology should be strictly supervised. According to the "Regulations on the Administration of Clinical Application of New Biomedical Technology", both clinical research and translational application of new biomedical technologies can only be conducted in top-class hospitals with relevant technology and supervision conditions. This regulation limits a relatively high threshold of access, as top-class hospitals are equipped with advanced medical equipment and medical professional staff, and the risk of clinical application of new biomedical technologies is lowered at a certain extent. However, this paper believes that it is necessary to add some regulations on daily supervision and carry out regular and meticulous supervision on relevant institutions to ensure the reasonable application of human enhancement technology. For example, the equipment used in the technology and the technical operation process should be inspected daily.

For medical institutions implementing human enhancement technology, hierarchical supervision can be adopted. Classification regulation refers to the situation of different medical institutions to take regulatory measures, in order to follow the principle of proportion, to achieve the optimal regulation effect, such as can be classified according to the agency's credit rating and criminal records, 
to not violate compasses record low density of regulatory agencies can take, but for poor credit, criminal records many medical institutions must carry on the strict regulation. It is recommended that the following provisions be made: 1) Medical facilities should be guided by a panel of experts from the health administration to conduct regular self-inspections and report promptly on the use of human enhancement technologies in the institution. 2) The report of the medical institution should be comprehensive and perfect, not only to report the daily operation of the institution, but also to complete the report of the specific situation of the medical dispute, including the specific background, the course of the incident, the consequences of the incident, the treatment method, the follow-up arrangement, etc. 3) If a medical institution fails to timely report its technology use and dispute settlement, or if there is fraud in the report of a medical institution, the health administrative department shall take certain punitive measures against it. In serious cases, the qualification of the medical institution to implement human enhancement technology may be cancelled.

\section{Conclusion}

Human enhancement is closely related to human life and health. Using the power of science and technology interferes with the nature of human survival and reproduction to some extent. Under the current technological conditions, human enhancement technology can enhance human's own ability and well-being through drugs, genetic modification and other ways.

However, we should be aware that any new biomedical technology has a great potential to cause a wave of applications. And this irrational rush to use tends to obscure the risks behind emerging technologies. In order to control risk, avoid improper use of technology pose a threat to the individual and society, even derogatory remarks about human dignity, incompatible with social justice, so be sure to at the legal level for all of these risks, foresee human enhancement may lead to legal risks in advance, and set up relevant legal regulation system.

From the current situation of China, compared with the rapid progress of technology, there are still some deficiencies in relevant legislation, unable to respond to the challenges brought by technology in a timely manner. Therefore, how to respond to the challenges of technology, neither "isolate", to promote the development of science and technology, to protect the freedom of scientific research, also can't "too far", to protect the people's life and health and social stability, and how to balance the relationship between the technology development and the social public interests, this is we have to solve the problem.

Under the current social background, China should find out the most suitable way of legal regulation of human enhancement technology. In addition, China should actively learn from foreign experience, and improve the relevant laws of human enhancement as soon as possible, clarify the bottom line of human enhancement, set up the code of conduct, determine clear rules to guide, form a scientific and rational social atmosphere, and improve the people's scientific literacy, in order to achieve the ideal regulation effect. 


\section{Conflicts of Interest}

The author declares no conflicts of interest regarding the publication of this paper.

\section{References}

Adams, H. (2010). A Human Germline Modification Scale. Journal of Law Medicine \& Ethics, 32, 164-173. https://doi.org/10.1111/j.1748-720X.2004.tb00462.x

Bostrom, N., \& Sandberg, A. (2009). Cognitive Enhancement: Methods, Ethics, Regulatory Challenges. Science \& Engineering Ethics, 15, 311-341. https://doi.org/10.1007/s11948-009-9142-5

Chadwick, R., \& Felicity, R. (2008). Therapy, Enhancement and Improvement. In B. Gordijn, \& R. Chadwick (Eds), Medical Enhancement and Posthumanity (pp. 25-37). Berlin: Springer. https://doi.org/10.1007/978-1-4020-8852-0_3

Douglas, T. (2014). Moral Enhancement. In R. L. Sandler (Ed), Ethics and Emerging Technologies (pp. 235-251). London: Palgrave Macmillan. https://doi.org/10.1057/9781137349088_16

Earp, B. D., Sandberg, A., Kahane, G., \& Savulescu, J. (2014). When Is Diminishment a Form of Enhancement? Rethinking the Enhancement Debate in Biomedical Ethics. Frontiers in Systems Neuroscience, 8, Article No. 12. https://doi.org/10.3389/fnsys.2014.00012

Feng, Y. (2012). A Philosophical Exploration of Human Enhancement Based on Nanotechnology. Master's Thesis, Dalian: Dalian University of Technology.

Giubilini, A., \& Sanyal, S. (2015). The Ethics of Human Enhancement. Philosophy Compass, 10, 233-243. https://doi.org/10.1111/phc3.12208

Hong, X. H. (2011). On the Legal Nature of Medical Relationship. Knowledge Economy, No. 23, 24.

Javor, A., Koller, M., Lee, N., Chamberlain, L., \& Ransmayr, G. (2013). Neuromarketing and Consumer Neuroscience: Contributions to Neurology. BMC Neurology, 13, Article No. 13. https://doi.org/10.1186/1471-2377-13-13

Jiang, X. (2015). Ethical Research on Human Enhancement Technology. Master's Thesis, Nanjing: Southeast University.

Khushf, G. (2008). Stage Two Enhancements. In F. Jotterand (Ed.), Emerging Conceptual, Ethical and Policy Issues in Bionanotechnology (pp. 203-218). Dordrecht: Springer. https://doi.org/10.1007/978-1-4020-8649-6_12

Levenson, R. W. (1994). Human Emotions: A Functional View. In P. Ekman, \& R .J. Davidson (Eds.), The Nature of Emotion: Fundamental Questions (pp. 123-126). New York, NY: Oxford University Press.

Mehlman, M. J., \& Botkin, J. R. (1998). Access to the Genome: The Challenge to Equality. Washington DC: Georgetown University Press.

Persson, I., \& Savulescu, J. (2012). Unfit for the Future: The Need for Moral Enhancement. Oxford: Oxford University Press. https://doi.org/10.1093/acprof:oso/9780199653645.001.0001

Qiu, R. Z. (2008). The Philosophical and Ethical Issues of Human Enhancement. Philosophical Trends, No. 2, 33-39.

Savulescu, J. (2010). Justice, Fairness, and Enhancement. Annals of the New York Academy of Sciences, 1093, 321-338. https://doi.org/10.1196/annals.1382.021 
Wu, Z. X. (2018). Research on the Burden of Proof in the Dispute of Diagnosis and Treatment Damage. Applicable Law, No. 3, 44-49.

Zheng, Q. S. (2020). A Study on Some Judicial Practices of Medical Damage Liability. Master's Thesis, Changchun: Changchun University of Science and Technology. 